\title{
Not Just in English: Government Information in Other Languages
}

\section{Getting Started with Docs in Other Languages}

\section{Jane Canfield}

n a 1995 response letter to a request from Senator Richard Shelby to identify how many government documents are published in languages other than English, the General Accounting Office (GAO) identified 265 documents published from 1990 to $1994 .{ }^{1}$ Of those documents, 50 had been published by the Social Security Administration, and 83 percent were written in Spanish. Today, a quick search in the Catalog of Government Publications (CGP) identifies 7,047 documents in Spanish.

Since I am the coordinator of a depository library in the territory of Puerto Rico, nearly all of my users speak Spanish and prefer information in Spanish. So, over the last twelve years, I have learned about documents in Spanish and am branching out to other languages. The need for government information in other languages is backed up by the increasing numbers of persons in the United States who speak a language other than English (LOTE) at home. In the Census Bureau publication Language Projections 2010-2020, the Bureau indicates that the use of a language other than English at home has increased by 148 percent. According to this same document, each of 13 languages have more than 500,000 speakers: Spanish, French, Italian, Portuguese, German, Russian, Polish, Hindi, Chinese, Korean, Vietnamese, Tagalog, and Arabic. ${ }^{2}$

In People Who Spoke a Language Other than English at Home by Hispanic Origin and Race: 2009, the Census Bureau indicated that 77 percent of those who identified as Asian and 76 percent of those who identified as Hispanic divulged that they speak a language other than English at home. ${ }^{3}$ The states with the most speakers of a language other than English at home are California (43 percent), New Mexico (36 percent), and Texas (34 percent). ${ }^{4}$

These statistics indicate that all of us working in libraries and providing government information will encounter speakers of other languages who need information. How do you begin to provide this information? Start by identifying what languages are spoken in your area. Users of the library, communities of immigrants, newspapers in other languages, and businesses which provide services in other languages are good indicators. Then, ask your library users what they need in other languages and involve other library staff in the process. This can be done informally when users come to the library or more formally through focus groups or community surveys.

To get started on finding the resources, here are some ideas. In the CGP, do a search for "publications in _____" filling in the blank with the language needed. In www.usa.gov/ the same search will yield multiple results. The usa.gov website can also be changed to Spanish and allows for searches using Spanish vocabulary. An individual search of various agencies and government websites will also provide results in multiple languages. My search in various agencies turned up 28 distinct languages with government publications including languages as diverse as Bengali, Chamorro, Hmong, Samoan, Thai, Urdu, Farsi, Hindi, and Greek among others. Table 1 provides a sampling of seven agencies and websites with information on the languages in which each publishes.

Table 1. Other than English Publications of Selected Federal Agencies

\begin{tabular}{|c|c|c|c|c|c|c|c|c|}
\hline Agency & Internet Address & Arabic & Chinese & French & $\begin{array}{l}\text { Haitian } \\
\text { Creole }\end{array}$ & Japanese & Korean & Spanish \\
\hline Food and Drug Administration & https://www.fda.gov/ & $x$ & $x$ & $x$ & $x$ & $x$ & $\mathrm{x}$ & $\mathrm{x}$ \\
\hline $\begin{array}{l}\text { Occupational Safety and } \\
\text { Health Administration }\end{array}$ & https://www.osha.gov/ & & & & & & & $x$ \\
\hline US Citizenship and Immigration Services & https://www.uscis.gov/ & $x$ & $x$ & & & & & $x$ \\
\hline $\begin{array}{l}\text { Equal Opportunity } \\
\text { Employment Commission }\end{array}$ & https://www.eeoc.gov/ & $x$ & $x$ & & $x$ & & & $x$ \\
\hline Official Medicare site & https://www.medicare.gov/ & $x$ & $x$ & $x$ & & $x$ & $x$ & $x$ \\
\hline Social Security Administration & https://www.ssa.gov/ & $x$ & $x$ & $x$ & $x$ & $x$ & $x$ & $x$ \\
\hline Medline Plus & https://medlineplus.gov/ & $x$ & $x$ & $x$ & $x$ & $x$ & $x$ & $x$ \\
\hline
\end{tabular}

$\mathrm{X}$ indicates information present in the language. 
The diversity of languages spoken in the United States is amazing and continues to grow. The federal government provides information in a surprising number of languages. Those of us who work in government information and have users who speak other languages, should be helping those users to find information to help them adapt to life in the United States. If we can do that in their native languages, then we are helping them to feel welcome.

I look forward to writing this column in the future and plan to cover specific agencies and websites which provide information in other languages. I also plan to cover topics such as education, health, housing, aging, immigration and other issues of interest to speakers of other languages. I would welcome suggestions from readers of this column on topics and agencies to include.

Jane Canfield (jcanfield@pucpr.edu), Government Information Coordinator, Pontifical Catholic University of Puerto Rico

\section{References}

1. United States General Accounting Office, GAO/GGD95-243R, Federal Foreign Language Documents, 1995.

2. Hyon B. Shin and Jennifer Ortman, Language Projections: 2010-2020 (Washington, DC: US Census Bureau, 2011).

3. Tallese D. Johnson et al., American Community Survey Briefs: People Who Spoke a Language Other Than English at Home by Hispanic Origin and Race: 2009 (Washington, DC: US Census Bureau, 2010).

4. People Who Spoke a Language Other than English: 2009 (Washington, DC: US Census Bureau, 2009). 